\title{
OFICINA DE HISTÓRIA DE ALAGOAS: UM RELATO DE EXPERIÊNCIA NA ESCOLA ESTADUAL COSTA REGO - ARAPIRACA/AL
}

\author{
Sebastiana Luciene Silva dos Santos ${ }^{1}$
}

\begin{abstract}
RESUMO: Este relato tem como objetivo divulgar um projeto de extensão desenvolvido na Escola Estadual Costa Rego, localizada no município de Arapiraca, agreste de Alagoas. O objetivo do projeto foi oferecer uma oficina sobre a história de Alagoas, uma vez ter sido diagnosticado, por meio de entrevista com a coordenadora pedagógica, que esse tema não era oferecido pela escola devido à falta de horário disponível para os professores de História ministrarem a disciplina. A oficina incluiu aulas expositivas, montagem de cartazes e exposição de fotografias e teve como público-alvo duas turmas de ensino médio da referida escola.
\end{abstract}

PALAVRAS-CHAVE: História de Alagoas. Ensino. Extensão.

\section{Workshop on the history of Alagoas: an experience report lived in Costa Rego state school,} Arapiraca, state of Alagoas, Brazil

\begin{abstract}
This experience report aims to promote an extension project developed in Costa Rego state school, in Arapiraca, state of Alagoas, Brazil. The project aimed to offer a workshop on the history of Alagoas, once the education coordinator informed through an interview that his theme was not taught in the school due to the few time available for history teachers to teach the subject. The workshop, attended by two high school groups, consisted of lectures, poster design and exhibition of photographs.
\end{abstract}

KEYWORDS: History of Alagoas. Education. Extension.

Entendendo a importância da extensão universitária como elo entre a Universidade e a sociedade, este trabalho tem como objetivo relatar como ocorreu a Oficina de História de Alagoas, desenvolvida por acadêmicos do curso de História da Universidade Estadual de Alagoas (UNEAL), sendo o primeiro trabalho extensionista dos acadêmicos envolvidos.

O projeto contemplou duas turmas de $3^{\circ}$ ano do ensino médio da Escola Estadual Costa Rego e trouxe como metodologia a utilização de aulas expositivas com as temáticas: "O ofício do historiador", "Alagoas Colonial", "Alagoas Império" e "Alagoas República", culminando com uma exposição de fotografias sobre os municípios alagoanos.

Além das aulas expositivas, foi solicitado aos alunos participantes da oficina que elaborassem cartazes e linhas do tempo. Também foram estabelecidos momentos de diálogo e discussão sobre a história alagoana e realizada uma exposição de fotografias dos municípios alagoanos, para que os alunos observassem as transformações ocorridas ao longo do tempo nesses municípios, conforme imagens abaixo:

\footnotetext{
${ }^{1}$ Graduada em História pela Universidade Estadual de Alagoas, assistente em serviços educacionais na mesma instituição (sissi2404@hotmail.com).
} 
Figura 1 - Praça Marques da Silva, Arapiraca-AL, na década de 1950.

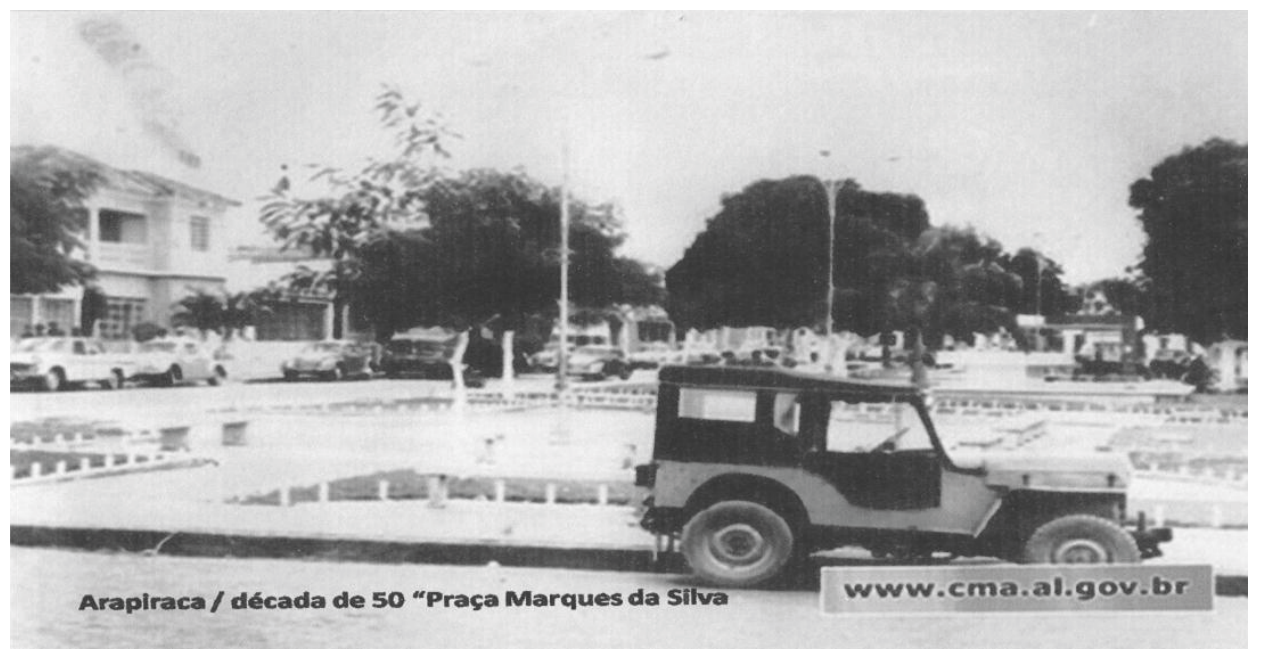

Fonte: www.cma.al.gov.br.

Figura 2 - Praça Marques da Silva, Arapiraca-AL, 2008.

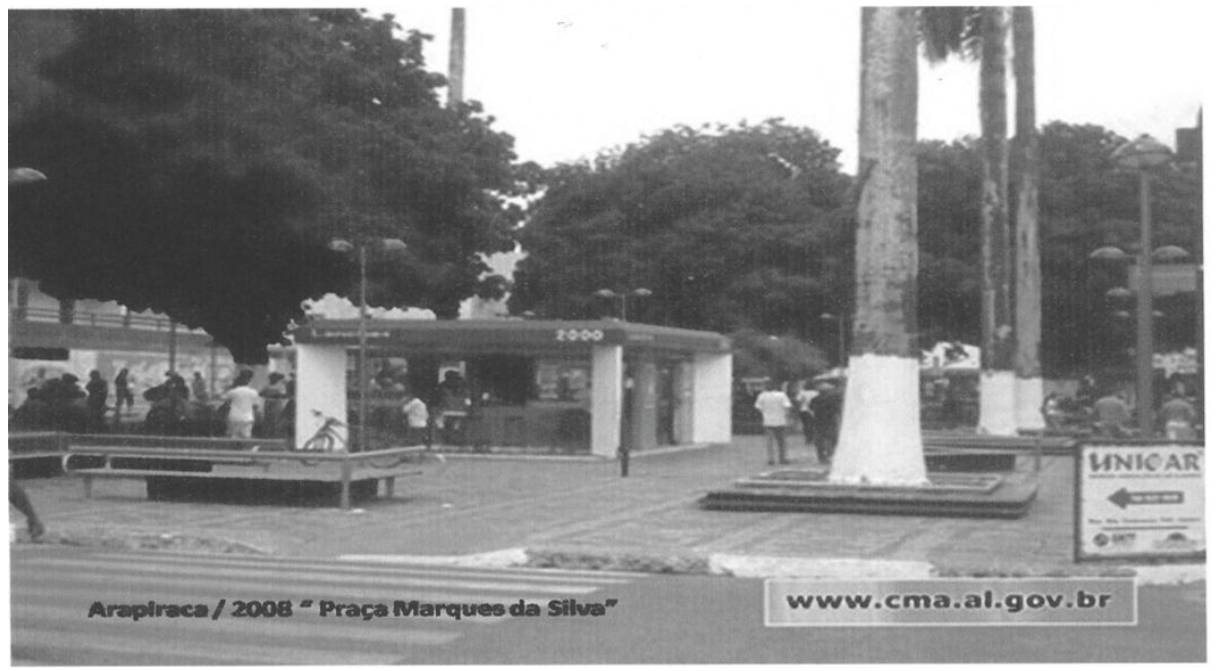

Fonte: www.cma.al.gov.br.

O projeto contribuiu para o desenvolvimento das habilidades docentes dos acadêmicos envolvidos na realização da oficina, uma vez que ambos cursavam licenciatura em História. Contribuiu também com a experiência decorrente do contato com os alunos em sala de aula, além de possibilitar a iniciação deles nas ações de extensão da UNEAL.

Para os alunos, a proposta propiciou-lhes aprender um pouco mais sobre a história de Alagoas e a compreender melhor a realidade que os cerca, atendendo, assim, a necessidade relatada pelos próprios estudantes quando mencionaram, durante divulgação do projeto na escola, que não tiveram esse ensino em nenhum momento da educação básica e ressaltaram que tinham curiosidade em conhecer a história do estado em que vivem.

Inicialmente, foram abordadas as temáticas referentes à política, economia e cultura alagoana no decorrer de sua formação, com ênfase para Alagoas Colonial, Alagoas Imperial e Alagoas República, buscando entender a configuração do estado a partir de 
seu processo histórico. Em seguida, os alunos foram orientados para a produção de atividades relacionadas às temáticas que mais lhes chamaram a atenção.

Na rede estadual de ensino, a disciplina de História de Alagoas está inserida na parte diversificada da matriz curricular. A orientação estadual consolidada pela Portaria $\mathrm{n}^{\circ} 18$, de 30 de janeiro de 2009, da Secretaria Estadual de Educação e Esporte de Alagoas é de que haja uma hora semanal de ensino de História de Alagoas no $8^{\circ}$ e $9^{\circ}$ anos do ensino fundamental, ficando a critério das escolas a metodologia utilizada.

O que se observa, previamente, é que praticamente não há ensino de História de Alagoas, pois, mesmo quando a escola adota essa disciplina, uma série de fatores, que vão desde falta de material didático à organização do horário das aulas, impede um ensino de qualidade.

Mesmo com as dificuldades encontradas para inserção da disciplina de História de Alagoas é possível proporcionar momentos em que os alunos tenham acesso a informações referentes ao nosso estado. A Oficina de História de Alagoas visou justamente esse objetivo: fazer com que os alunos tenham contato com a história alagoana.

Outro ponto relevante é o fato da disciplina em questão estar inserida no conteúdo programático dos editais de vestibular. Dessa forma, ressalta-se a importância dos alunos terem acesso aos conteúdos referentes ao estado de Alagoas.

Para os acadêmicos que se envolveram nessa ação extensionista, a importância de tal participação foi muito significativa, pois proporcionou o primeiro contato com a extensão universitária, despertando o gosto para envolvimentos futuros, além de contribuir com a formação docente por meio de toda a ação de ensino e preparação de aulas necessárias para a ministração da oficina.

Para os alunos da escola, a satisfação e o interesse foram nítidos e, no intuito de formalizar suas falas, foi solicitado que eles escrevessem sobre a importância de estudar a história de seu estado. Abaixo seguem algumas das respostas obtidas:

É importante porque acabamos de ter mais conhecimento do que se passa no nosso estado, estudando a história do nosso estado podemos tirar dúvidas (Aluno A).

É de adquirir conhecimentos, e saber mais sobre o estado em que moramos. (Aluno B).

É saber os fatos ocorridos, como o estado foi criado, por qual processo ele passou para chegar até os dias de hoje. Saber a origem dos primeiros habitantes, quem foram os colonizadores. (Aluno C).

De uma forma geral, as falas mostram que a ação extensionista desenvolvida trouxe um contato inicial sobre história de Alagoas para os alunos, fazendo com que eles se interessem mais por esse assunto e conheçam, mesmo que de forma breve e introdutória, alguns aspectos da história alagoana.

\section{REFERÊNCIAS}

BITTENCOURT, C. M. F. Ensino de história: fundamentos e métodos. São Paulo: Cortez, 2004. (Coleção Docência em Formação). 
ALAGOAS. Secretaria de Educação e do Esporte. Portaria no 018, de 30 de janeiro de 2009. Maceió: SEE, 2009.

GOMES, F. Palmares. São Paulo: Contexto, 2005.

BRANDÃO, M. História de Alagoas. Arapiraca: Edual, 2004.

Submetido em 23 de junho de 2014.

Aprovado em 7 de agosto de 2014. 